\title{
Natural Regeneration Status of the Ground Water Forest in Nech Sar National Park, Ethiopia
}

\author{
Molla Mekonnen Alemu ${ }^{1}$ \\ ${ }^{1}$ De Montfort University, Leicester, UK \\ Correspondence: Molla Mekonnen Alemu, De Montfort University, Leicester, UK. E-mail: \\ mollamekonnen@gmail.com \\ Received: February 22, 2017 \\ Accepted: March 3, 2017 \\ Online Published: March 7, 2017 \\ doi:10.5539/enrr.v7n2p1 \\ URL: https://doi.org/10.5539/enrr.v7n2p1
}

\begin{abstract}
Nech Sar National Park hosts a variety of unique terrestrial and aquatic features. The ground water forest of the park is characterized by dense canopy cover, evergreen, none rainfall dependent out of its biome region, rich in ground water and associated wetlands and mixed shrub land vegetation structure. Since ecosystem management is solidly dependent on localized factors, the research was carried out to explore the regeneration status of the ground water woody vegetation of Nech Sar National Park as it is a crucial element of identifying environmental as well as human induced factors that are affecting the restoration potentials of the vegetation. A total of 36 experimental plots were employed along five different transects that were laid out systematically so as to explore the regeneration status of the major woody tree species of the ground water vegetation of the park. The findings showed that, the ground water vegetation is at high risk of natural regeneration that needs the urgent interference of all concerned Government and development partners in averting the selective cutting of trees so as to meet the ever increasing household energy demand of Arba Minch city.
\end{abstract}

Key Words: Regeneration, National Park, Ground Water Forest

\section{Introduction}

The comprehensive management of natural capitals which humans depend for their wellbeing encompasses the sustainable production of yield. Land resources which are being used for the production of goods and services, be it grasslands, water bodies, wildlife, forests, etc. has to be maintained in a sustainable way if their service has to continue so as to fulfill the needs of the present generation without compromising the benefits of generations to come.

As a result of its ecological diversity (rift valley, highlands, lowlands, etc.), the horn of Africa is usually considered as an important hot spot of global biodiversity in relation to the amount of plants and animals species as well as the diversity of the ecosystems it comprises (Swara, 1992; UNEP, 2006).

Due to the varied ecological set ups, Ethiopia owns a significant number of endemic plant and animal species. Ethiopia is also being considered among the Vavilov Center (centers of origin) for the world's genetic resources (Van de Laar, 1988, cited in Zenebe 1999; Edwards \& Ensermu, 1999; Sayer et al., 1992; Shibru \& Martha, 1998; Demel \& Mulugeta, 2006).

The biological diversity of the country is estimated to be made up of 6500 - 7000 higher plant species (conifers, angiosperms, and ferns), $12 \%$ of which are endemic. The documented animal complement consists of 277 species of mammals, 861 species of birds, 20 species of reptiles, 63 species of amphibians, 150 species of fish and 324 species of butter flies. In terms of endemism, it comprises 31 mammals, 28 birds, 9 reptiles, 24 amphibians, 4 fish, and 7 butterfly species (Ali \& Zeleke, 2003; EWCA, 2015; Michael et al., 2001).

Marco and Raffaello (2012) defined natural restoration or regeneration as a process by which the forest is renewed naturally which is created as a result the emergence of young plants from seeds (seedlings). They also explained as forest trees encounter different phases of life cycle which includes, seedling phase, characterized by intensive competition and high mortality; a juvenile intensive height growth phase, which determines how fast growing trees reach the over-story canopy layer; and finally the maturity phase, which is described by the dominance of canopy and the onset of reproduction and recruitment processes. 
Undisturbed habitats can easily obtain a younger generation of trees from self-seeding (soil seed bank), provided that climatic and soil factors are conducive for the growth and development of plants. However, as a result of the increased deforestation many of the natural habitats are facing a high risk of natural regeneration which poses a threat on species extinction. The objective of this study is, therefore, to carry out an assessment on the natural regeneration status and prospects of the ground water woody vegetation of Nech Sar National Park.

\section{Materials and Methods}

\subsection{Description of the Study Area}

The study is conducted in Nech-Sar national park. It is located in the south nation, nationalities and peoples state of Ethiopia. The park is found right after the eastern edge of Arba Minch town, at about $510 \mathrm{Km}$ south of Addis Ababa and $270 \mathrm{Km}$ from Hawassa. The park lies within the floor of the Great Rift Valley and extends from $5^{\circ} 51$ $\mathrm{N}$ to $6^{\circ} 50^{\prime} \mathrm{N}$ and from $37^{\circ} 32^{\prime} \mathrm{E}$ to $37^{\circ} 48^{\prime} \mathrm{E}$ with an elevation varying between 1,108 and 1,650 above sea level. It covers an area of $514 \mathrm{Km} 2$ of which $85 \%$ is land and $15 \%$ is water (shores of Lake Abaya from the north and Lake Chamo in the south). Nech Sar National Park's greatest asset is its diverse combination of ground-water forest, savanna acacia forest, open savanna, escarpment walls, highland acacia forest, hot springs and lakeshores. Nech Sar's ecosystems provide habitats for the world's largest population of the endemic Swayne's hartebeest (EFDRE, 2008).

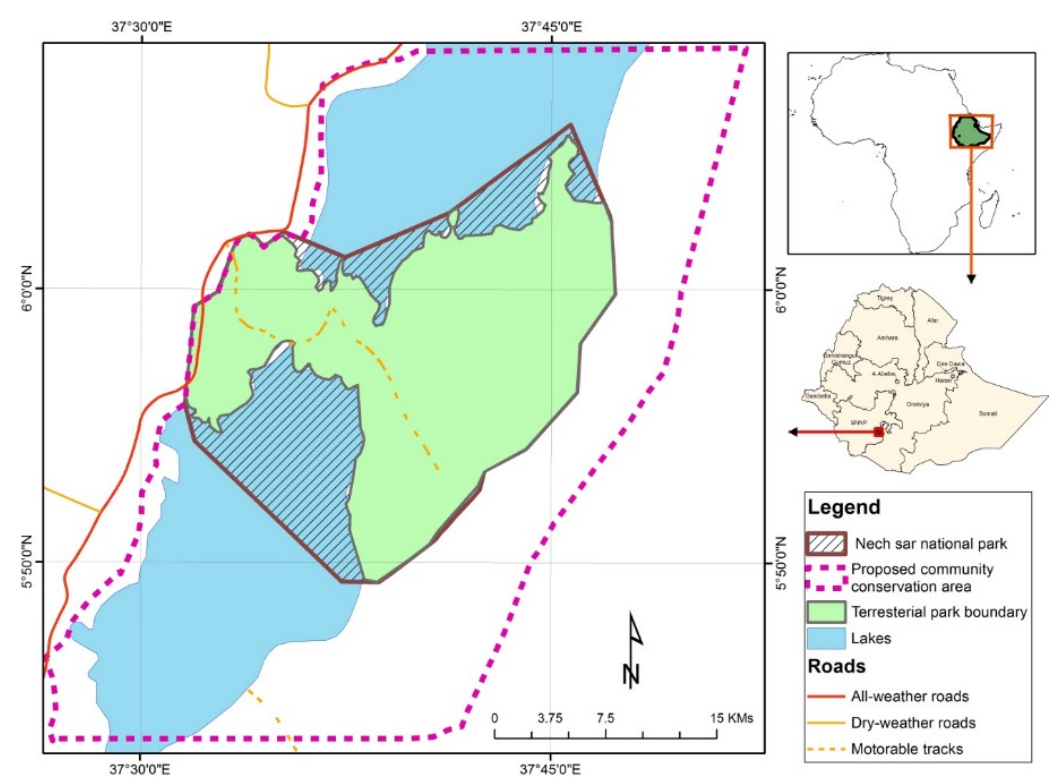

Figure 1. Location of the study area, Nech Sar National Park (EWCA, 2015b)

\subsection{Methods}

\subsubsection{Data Collection}

Examination of the population structures of plants, employing either height or diameter classes, will be used to provide a rough idea about the status of regeneration of woody plants (Tamrat, 1994; Demel, 1998; Mekuria et al., 1999; Tefera, 2001; Alemnew, 2001).

After having a reconnaissance survey of the park, to determine the population structure of the major woody plants of the Ground Water Woody Vegetation of the park, 36 (2 control) quadrates (plots) measuring $20 \mathrm{~m} \mathrm{X} 20$ $\mathrm{m}\left(400 \mathrm{~m}^{2}\right)$ were laid down along with five transects by making use of a GIS software, arc view (Figure, 2). The transects were laid out systematically and randomly in way of meeting the objective of the study.

Based on the level of human interference the plots were also categorized under three categories: protected, less and high human interference levels. Protected land management is the area of the park that falls under close supervision of the park management as a result of its proximity to the park's main office and the area is believed to be undisturbed by human interference. Less human interference is part of the park with a bit of human interference (not very far from the main office of the park) whereby fuel wood cutting and livestock grazing can be practiced sometimes; and high human interference is part of the park which is under high human interference as a result of fuel wood collection, charcoal making and livestock grazing activities. 


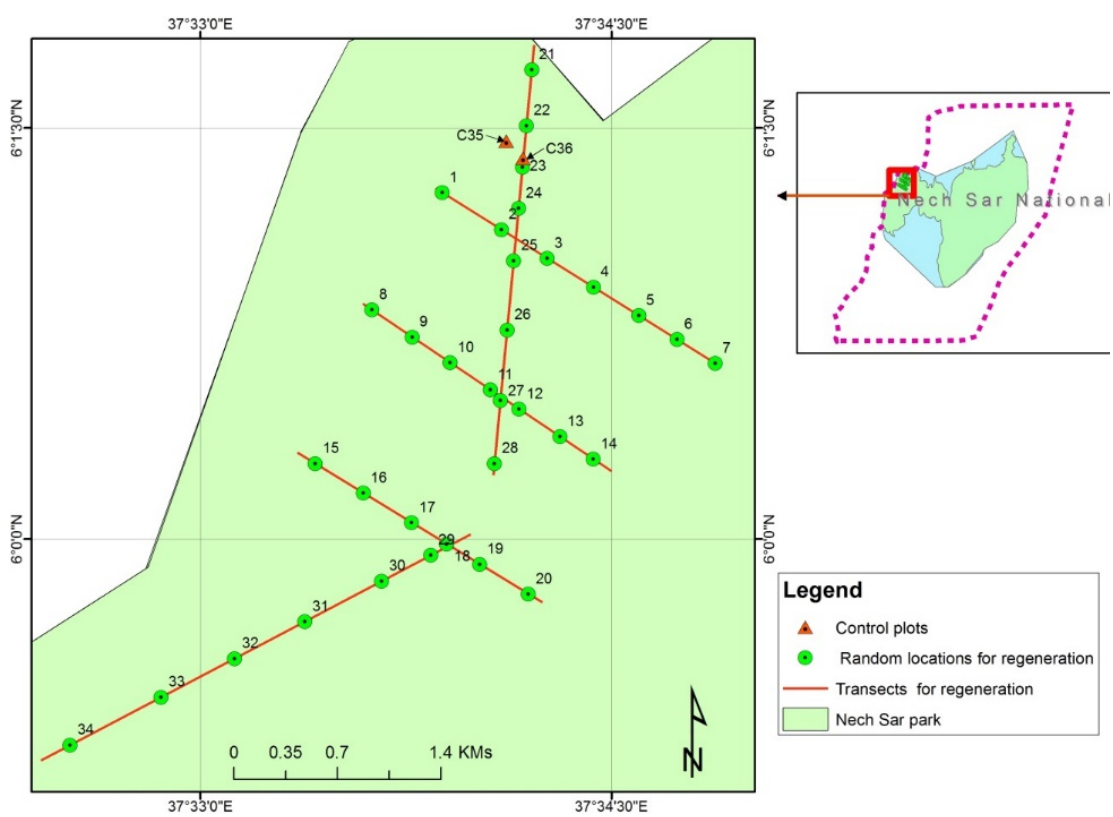

Figure 2. Transects lines with corresponding experimental plots

\subsection{Data Analysis}

Population structure, defined as the distribution of individuals in systematically defined height or diameter classes, provides the size/frequency profile of a species, used to analyse the structure of the population, also can explain the potentials and/or constraints of the future population dynamics of a site (Kindeya, 2003; Demel, 1997, cited in Aklilu, 2008).

Examination of the population structures of plants, employing either height or diameter classes, was used to provide a rough idea about the status of regeneration of woody plants (Demel, 1998; Kindeya, 2003; Swamy et al., 2000 cited in Emiru, 2002). Inverted J-shape frequency is an indicator of a healthy regeneration and good recruitment (Demel \& Feyera, 2003; Van Laar \& Akca, 1997, cited in Sarah, 2003). Thus, to comprehend the regeneration status of the ground water woody vegetation of the park in general and at a species level for some of the ecologically important species the population structures were constructed using frequency distribution of diameter classes.

Hence, to assess the regeneration status of woody plants, through examination of their population structures, all individuals encountered in the quadrats were grouped arbitrarily into: (i) height classes: $<0.5 \mathrm{~m}$ (seedlings), 0.5 $3 \mathrm{~m}$ (saplings) and $>3 \mathrm{~m}$ (trees); and (ii) diameter classes: $<2 \mathrm{~cm}, 2-4,4-6,6-8$, etc. centimeters $(\mathrm{cm})$. Then, histograms were drawn to see the population structure of the major woody plants.

\section{Results and Discussion}

The forest commission of UK (2016) defines Natural regeneration as "the process by which woodlands are restocked by trees that develop from seeds that fall and germinate in situ". Wang (2008) also said that "forest natural regeneration is a natural biological process of forest resource reproduction in ecosystem dynamics".

Soil seed bank is the major source of diversity, structure and natural regeneration for the greatest number of plants. Soil seed bank includes "all living seeds in a soil profile, including those on the soil surface" (Arne et al., 2014). In the case of protected areas, soil seed bank is a critical way of maintaining native plant species in a sustainable way. In areas where human interference caused for the degradation of vegetation, soil seed bank can be an effective way of restoring the native plant species. Factors like soil moisture, temperature, etc. will have an impact on the longevity and survival of the inputs from seeds. The duration of viability of seed's life in the bank is also different from one plant taxa to the other and hence the composition and diversity of seeds in a seed bank could be different when compared with the above ground vegetation cover (Nicole, 2006). Arne et al. (2014) also said that "soil seed banks vary much according to seed proximity, seed persistence and physiological state. Living seeds have been found in or on the soil for different durations, different seasons, at different depths, in different quantities and in different states of dormancy or procession to germination. Seeds in the soil seed bank may occur in or on the soil, but in many situations, there is continuity between seeds at the surface, partly buried and completely buried seeds". 
The natural regeneration of trees from the seeds requires sufficient amount of seed production, effective germination and necessary conditions for the growth of the seedlings. In addition to this, for the success of seedling growth, factors like availability of sufficient moisture, sunlight and edaphic factors will play a paramount role.

On the other hand, the growth of seedlings can always be challenged in various ways, especially under the protected areas context. Herbivorous wild animals are largely dependent on grass or other palatable plant species and the fate of seedlings can be negative if livestock or wild animals depend on them for depredation. Seedlings can also be attached by insects and diseases very easily. Drought and frost can also easily affect the survival of seedlings (Claralynn \& Yana, 2007).

In terms of cost, the natural regeneration of trees is also a feasible low cost option of maintaining natural habitats by making use of the annual seed crop as compared to artificial regeneration programmes.

Lonchocarpus laxiflorus, Euclea divinorum, Prunus africana Maytenus undata and Syzygium guineense are the most dominant trees of the ground water vegetation of Nech Sar National Park. The vegetation has a very dense green canopy cover which is dominated by long and matured trees and their characteristic is briefed as follows.

Table 1. Dominant trees of the ground water vegetation of NNP and their local name

\begin{tabular}{lll}
\hline S.N. & Scientific Name & Vernacular Name \\
\hline 1. & Lonchocarpus laxiflorus & Hasso \\
2. & Maytenus undata & Checho \\
3. & Syzygium guineense & Doqima \\
4. & Prunus Africana & Tikur Enchet \\
5. & Euclea divinorum & Dedeho \\
\hline
\end{tabular}

\section{Lonchocarpus laxiflorus}

Lonchocarpus laxiflorus is well known for being one of the sources of fodder for wildlife It is a tree plant which falls under the Plantae Kingdom, Fabaceae family and Class Angiosperm and a species of legume. It is a plant which can go up to $5-6 \mathrm{~m}$ of height.

The bark of the plant is used as a sauce and spice for human food. Extracts from the bark, root and leaf of the tree are used to treat skin infections, parasitic infections, and liver complications for humans. In the field of agriculture, leaf and bark extracts can help as an insecticide (Burkill, 1995).

\section{Maytenus undata}

Maytenus undata can have a height of $5 \mathrm{~m}$. It belongs to family Celastraceae and Class Angiosperm. Extracts of the plant are believed to be used as anti-asthmatic, stomach treatment and anti-tumour (Tsholofelo et al., 2013).

\section{Syzygium guineense}

Syzygium guineense can grow up 10-25m in height. It falls under the family Myrtaceae (Paul and Quentin, 2004). Its fruits are edible by humans and animals. The fruit is also used to treat dysentery and extracts of the bark are also used as an antidiarrhoeic. The bark can however, be toxic and cause death to humans (Coates, 2002; Orwa et al., 2009).

\section{Prunus africana}

It is spiny shrub or tree which can go up to $10-25 \mathrm{~m}$ height. It is an angiosperm which belongs to the Family Rosaceae and Kingdom Plantae (Cunningham \& Mbenkum, 1993). The different parts of the plant have been used for a lot of medicinal values. For instance, the bark can be used to treat chest pains. Extracts of the bark are also used to treat benign prostate hypertrophy (Van Wyk et al., 1997).

\section{Euclea divinorum}

The tree can reach up to 6-15m height and it belongs to the family Ebenaceae. Extracts from the bark serve for dyeing skin, hides, wool, fibres, etc. The root extracts known to treat wounds, gastro-intestinal disturbances, cancer, skin infections, headaches, toothaches, arthritis, miscarriage, jaundice, snakebites and gonorrhea (Njuguna, 2005).

The population structure of the major trees across the different human interference levels is analyzed and put forward as follows. 

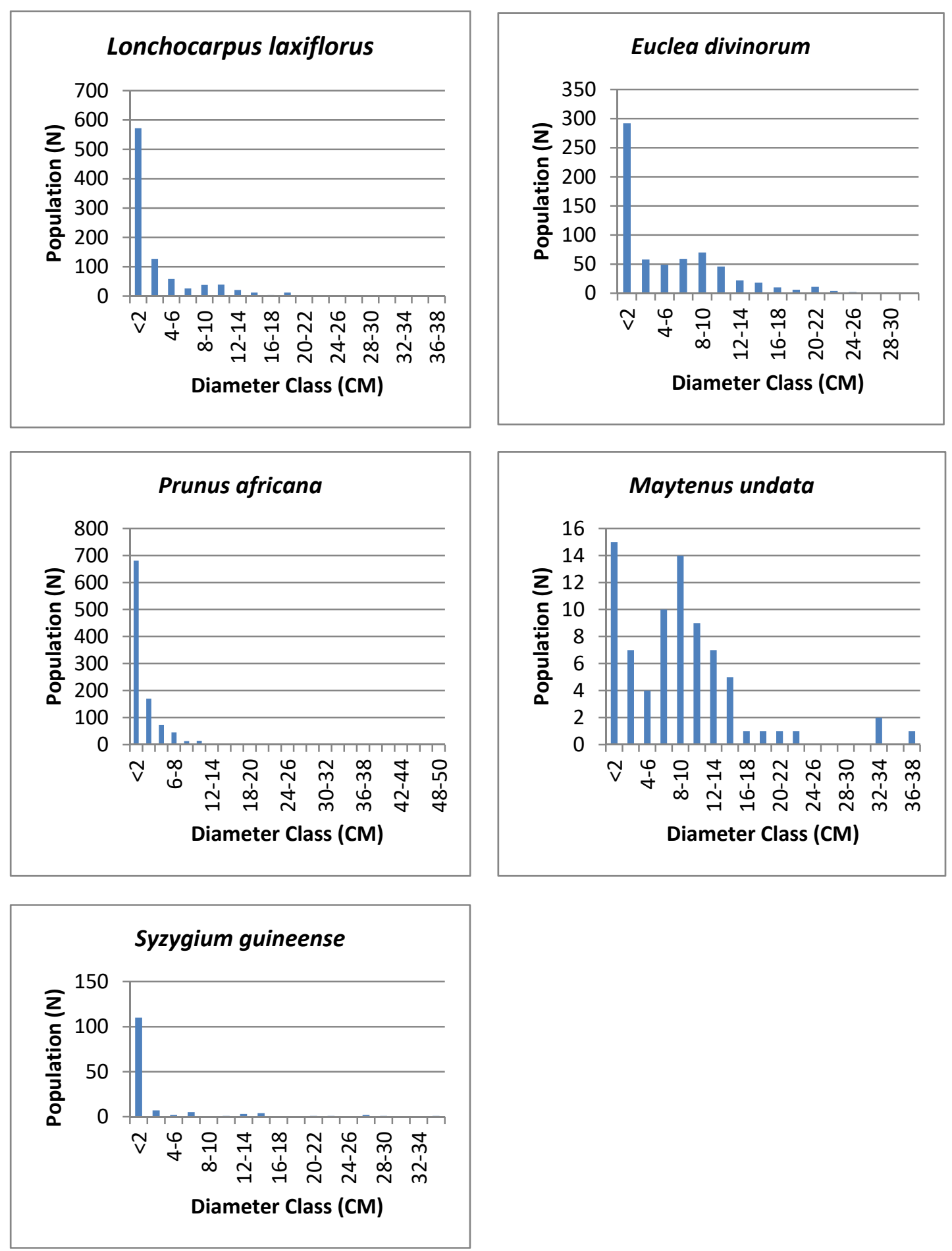

Figure 3. Population structure of the major trees in the protected area of the park 

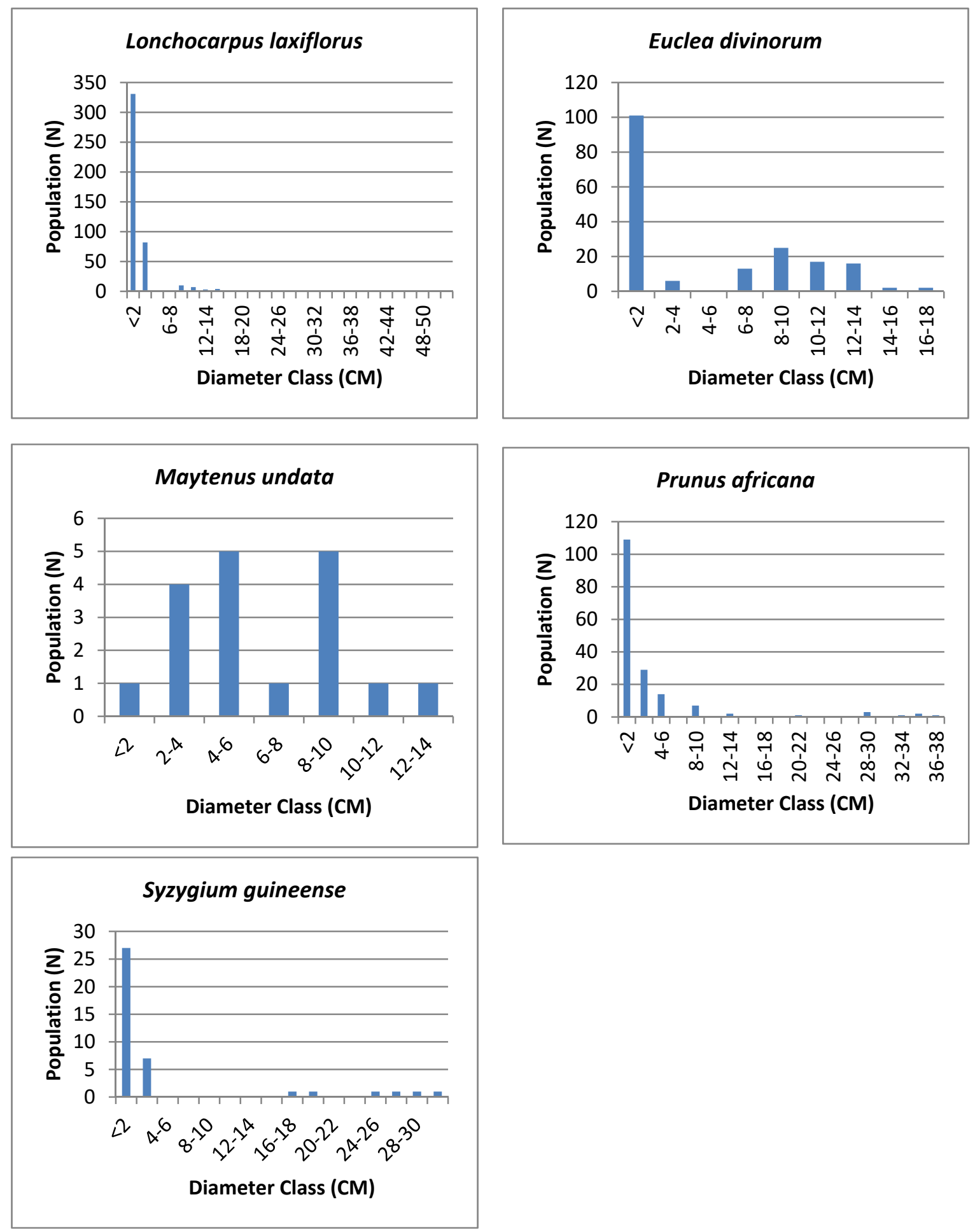

Figure 4. Population structure of the major trees in the less human interference area of the park 

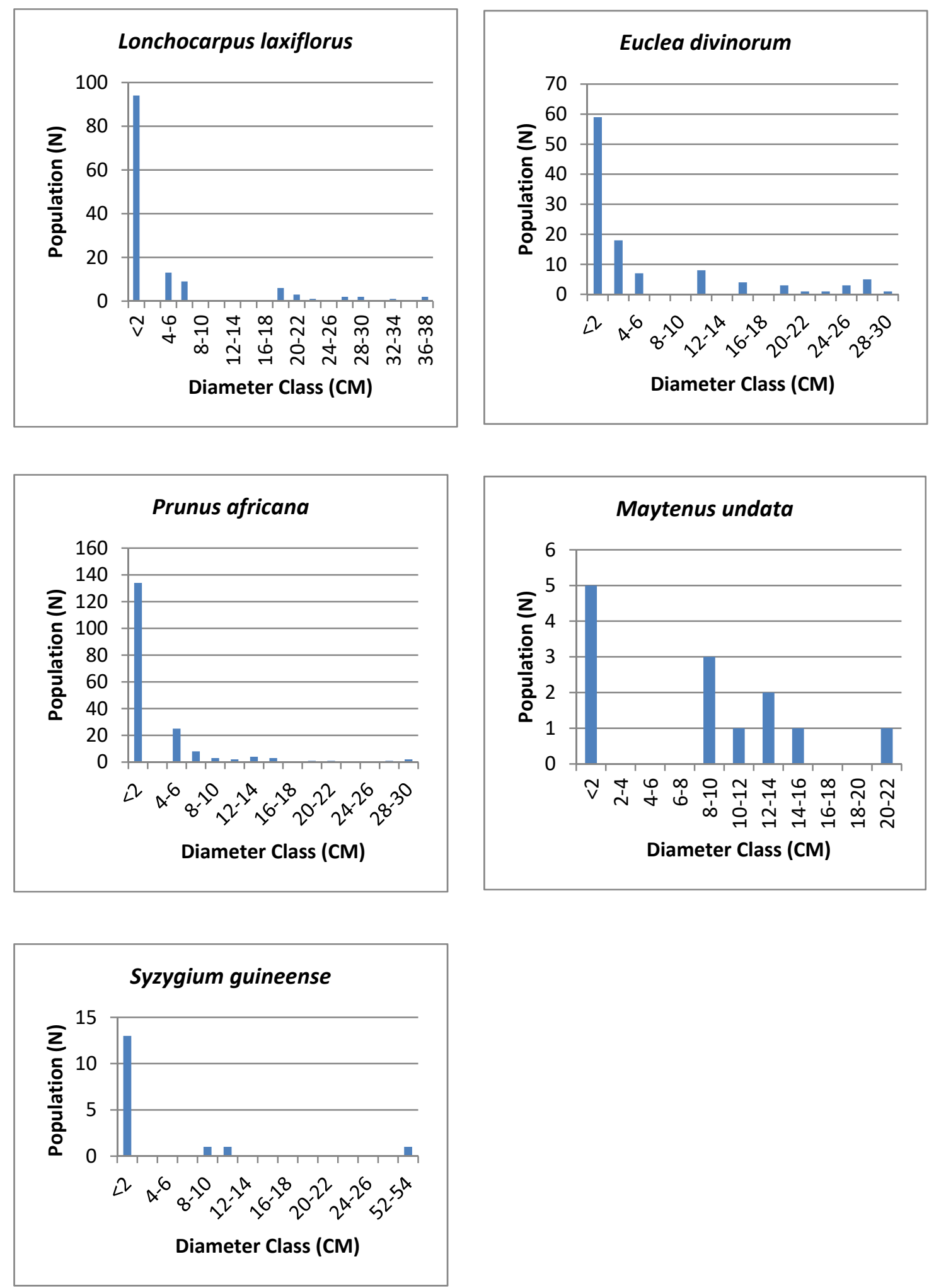

Figure 5. Population structure of the major trees in the high human interference area of the park 
In the protected zone/areas of the Nech Sar National Park vegetation, it is only the population structure of Lonchocarpus laxiflorus and Prunus africana which resembled an inverted J structure with a discontinuity on the upper diameter classes. The structures are mainly an attribute of the prevalence of a high number of seedlings which could mainly be related to the availability of moisture at the time of data collection. Maytenus undata, Euclea divinorum, and Syzygium guineense also exhibited a significant number of seedlings but, with irregular distribution on the middle and upper diameter classes. Thus, in the protected area it is only Lonchocarpus laxiflorus and Prunus Africana that has a promising regeneration potential (Figure 3).

In the less human interference area of the vegetation, Lonchocarpus laxiflorus, Prunus Africana and Euclea divinorum had a high number of seedlings. In this area, none of the trees exhibited an inverted $\mathrm{J}$ population structure as there are discontinuities in various lower and higher diameter categories which shows as the regeneration potential in this area is being affected by human interference (Figure 4).

The population structure of the major trees in the high human interference areas of the vegetation had a discontinuous structure across the different diameter classes which showed as the trees are not maintaining their natural regeneration (Figure 5).

The urban, peri-urban and rural communities of the Arba Minch city area are highly reliant on the woody vegetation of the park in order to meet their household energy demand. According to different reports, it is estimated that $98 \%$ of the household energy source of Arba Minch city is obtained from fuel wood that mainly comes from the forest of Nech Sar National Park (Abraham, 2015). Hence, selective cutting of trees for fuelwood, charcoal making and the need for woody construction materials are factors which affect the natural regeneration potential of the woody vegetation of Nech Sar National Park.

\section{Conclusion}

The most dominant tree species of the ground water vegetation of the park, Lonchocarpus laxiflorus, showed an inverted J- shape population structure in the protected land management type of the park, indicating as it is the only tree species which exhibited a natural regeneration potential followed by Euclea divinorum. Trees in the other management areas showed irregular diameter class distribution implying that the trees are not in a promising self-maintaining population structure. This very low potential of regeneration is caused by the selective cutting of trees in order to meet the ever increasing energy demand of the city of Arba Minch. Therefore, if the woody vegetation of the park has to continue with its ecosystem services; local, regional and federal institutions and development partners have to work in partnership in ameliorating the energy demands of the city of Arba Minch. Apart from this, awareness development, law enforcement and alternative livelihoods development efforts will also play a pivotal role so as to save the diminishing forest resources of the park.

\section{Reference}

Aleligne, A. (2001). Diversity and socio-economic importance of woody plants on the peninsula of Zegie, northwestern Ethiopia: implication for their sustainable utilization. Swedish University of Agricultural Sciences.

Argaw, M., Teketay, D., \& Olsson, M. (1999). Soil seed flora, germination, and regeneration pattern of woody species in Acacia woodland of the rift valley of Ethiopia. Journal of Arid Environments.

Bekele, T. (1994). Studies on remnant afromontane forests on the central plateau of Shewa, Ethiopia. Uppsala University.

Birhane, E. (2002). Actual and potential contributions of enclosures to enhance biodiversity in dry lands of Eastern Tigray, with particular emphasis on woody plants. MSc. thesis. Swedish University of Agricultural Sciences.

Borghetti, M., \& Giannini, R. (2012). Natural Regeneration in Woodland Management. University of Basilicata, Potenza, Italy and University of Firenze, Italy. Biodiversity Conservation and Habitat Management Volume I.

Braat, P., \& Brink, T. (2008). The case of not meeting the 2010 biodiversity target. Wageningen, Netherlands.

Burkill, H. M. (1995). The Useful Plants of West Tropical Africa (Vol. 3). Royal Botanic Gardens, Kew.

Coates Palgrave, M. (2002). Keith Coates Palgrave Trees of southern Africa (3 Ed.). Struik, Cape Town.

Cunningham, A. B., \& Mbenkum, F. T. (1993). Sustainability of harvesting Prunus africana bark in Cameroon: A medicinal plant in international trade. People and Plants working papers. Division of Ecological Sciences, UNESCO. 
Desse, A. M. (2015). Summary of Attractions, Challenges. Research, Management and Partnership Issues on Nech Sar National Park. Arba Minch, Ethiopia.

Duncan, D. (2012). A Study of Some of the Factors Affecting the Natural Regeneration of Tamarack (Larix Laricina) in Minnesota. School of Forestry, University of Minnesota.

EFDRE (Embassy of the Federal Democratic Republic of Ethiopia). (2015). Tourism, National Parks. Retrieved from http://www.Ethiopia-emb.or.jp/tourism_e/park/index.html\#04

EWCA (Ethiopian Wildlife Conservation Authority). (2015). Ethiopian Wildlife Conservation Authority. Retrieved March 13, 2015, from www.ewca.gov.et

EWCA. (2015b). Location Map of Nech Sar National Park on CD. Addis Ababa, Ethiopia.

FCUK (Forest Commission United Kingdom). (2016). Natural regeneration of broadleaved trees and shrubs. Retrieved October 18, 2016,from http://www.forestry.gov.uk/fr/INFD-5Z5GFE

Gebreegziabher, Z. (1999). Dessa'a Protected Area an Assessment of Human Impact, Evolutionary Pattern and Options for Sustainable Management Mekelle, Ethiopia.

Gebrehiwot, K. (1995). Scope for enhancing farm productivity through improved traditional agroforestry practices using native species of trees in Tigray, northern Ethiopia. M.Sc. Dissertation. University College of North Wales, Bangor, UK.

Gebrehiwot, K. (2003). Ecology and Management of Boswellia papyrifera (Del.) Hochst. Dry Forests in Tigray, Northern Ethiopia. Doctoral Dissertation submitted for the degree of Doctor of Forest Sciences of the Faculty of Forest Sciences and Forest Ecology Georg-August-University of Göttingen, Germany.

Jeffrey, A., \& McNeely, S. J. (2001). Common Ground, Common Future How Eco-agriculture Can Help Feed the World and Save Wild Biodiversity, Venezuela.

Lemenih, M., \& Teketay, D. (2006). Changes in soil seed bank composition and density following deforestation and subsequent cultivation of a tropical dry Afromontane forest in Ethiopia. Tropical Ecology, 47(1), 1-12.

Mengistu, T. (2001). The role of area closures in the recovery of woody vegetation in degraded hillsides of Biyo and Tiya, central and northern Ethiopia. Swedish University of Agricultural Sciences.

Michael, J., \& Catherine, A. (2001). Impacts of Conflict on Biodiversity and Protected Areas in Ethiopia. Washington, D.C.: Biodiversity Support Program.

Mohammed, A., \& Zeleke, A. A. (2003). The Status of Dorcas Gazelle in Ethiopia. Paper presented in the second workshop on the conservation and restoration of Sahelo-Saharan Antelopes. 1-5 May 2003Agadir, Morocco.

Mokoka, T. A., McGaw, L. J., Mdee, L. K., Bagla, V. P., Iwalewa, E. O., \& Eloff, J. N. (2013). Antimicrobial activity and cytotoxicity of triterpenes isolated from leaves of Maytenus undata (Celastraceae). BMC complementary and alternative medicine, 13(1), 111.

Negussie, A. (2008). The Damage of long horn beetle (Idactus spinipennis Gahan) on dry deciduous Boswellia woodlands in Central and Western Tigray, Northern Ethiopia (Doctoral dissertation, MSc thesis, Mekelle University, Mekelle, Tigray, Ethiopia).

Nicole, L. L. (2006). The Soil Seed Bank of an Oregon Montane Meadow: Consequences of Conifer Encroachment and Implications for Restoration. University of Washington, USA.

Njuguna, P. M. (2005). Euclea divinorum Hiern. [Internet] Record from PROTA4U. In P. C. M. Jansen, \& D. Cardon, (Ed.), PROTA (Plant Resources of Tropical Africa / Ressources végétales de l'Afrique tropicale), Wageningen, Netherlands. Retrieved August 21, 2016, from http://www.prota4u.org/search.asp

NunaMaker, C., \& Valachovic, Y. (2007). Forest Regeneration. Regents of the University of California, Division of Agriculture and Natural Resources.

Orwa, C., Mutua, A., Kindt, R., Jamnadass, R., \& Simons, A. (2009). Agroforestree database: a tree species reference and selection guide version 4.0. World Agroforestry Centre ICRAF, Nairobi, KE.

Saatkamp, A., Poschlod, P., \& Venable, D. L. (2014). The Functional Role of Soil Seed Banks in Natural Communities Institut Méditerranéen de Biodiversité et d'Ecologie (IMBE UMR CNRS 7263), Université d'Aix-Marseille, Marseille, France; CAB International. 
Senbeta, F., \& Teketay, D. (2003). Diversity, community types and population structure of woody plants in Kimphee forest, a unique nature reserve in southern Ethiopia. Ethiopian Journal of Biological Sciences, 2(2), 169-187.

Shimelse, S., Bekele, T., \& Mengistu, A. (2010). Floristic Diversity and Structure of Nechisar National Park, Ethiopia. Journal of the Drylands, 3(1).

Smith, P., \& Allen, Q. (2004). Field Guide to the Trees and Shrubs of the Miombo Woodlands (Kew, 2004).

Swara. (1992). East African Wildlife Society. Nairobi, Kenya.

Teketay D. (1999). Past and Present Activities, Achievements and Constraints in Forest Genetic Resources Conservation in Ethiopia.

Teketay D., \& Granström, A. (1995). Soil seed banks in dry afromontane forests of Ethiopia. Journal of Vegetation Science, 6.

Teketay, D. (1998). Germination of Acacia origena, A. pilispina and Pterolobium stellatum in response to different pre- sowing seed treatment, temprature, and light. Journal of Arid Environments, 38.

Tewolde-Berhan, S. (2003). Vegetation Improvement in Closed Areas, Grazing Land and Protected Forest in Tigray. Ethiopia. Göttingen, Germany.

UNEP. (2006). Africa Environment outlook 2 Sub Regional. Overview. Rome. Italy. pp 1

Van Wyk, B. E., Van Oudtshoorn, B., \& Gericke, N. (1997). Medicinal plants of South Africa. Briza Publications, Pretoria.

Wang, H., Li, G., Yu, D., \& Chen, Y. (2008). Barrier effect of litter layer on natural regeneration of forests: a review. Chinese Journal of Ecology.

WWF. (1990). Mission for the 1990s. Geneva, Switzerland.

\section{Copyrights}

Copyright for this article is retained by the author(s), with first publication rights granted to the journal.

This is an open-access article distributed under the terms and conditions of the Creative Commons Attribution license (http://creativecommons.org/licenses/by/4.0/). 